Bull. Mater. Sci., Vol. 21, No. 1, February 1998, pp. 99-103. (C Printed in India.

RAPID COMMUNICATION

\title{
Alloy-oxide equilibria in the system Pt-Rh-O
}

\author{
K T JACOB*, SHASHANK PRIYA and YOSHIO WASEDA ${ }^{\dagger}$ \\ Department of Metallurgy, Indian Institute of Science, Bangalore 560012 , India \\ ${ }^{\dagger}$ Research Centre for Metallurgical Process Engineering, Institute for Advanced Materials Processing, Tohoku \\ University, Sendai 980-77, Japan \\ MS received 12 January 1998
}

\begin{abstract}
The composition of $\mathrm{Pt}-\mathrm{Rh}$ alloys that co-exist with $\mathrm{Rh}_{2} \mathrm{O}_{3}$ in air have been identified by experiment at $1273 \mathrm{~K}$. The isothermal sections of the phase diagram for the ternary system Pt-Rh-O at $973 \mathrm{~K}$ and $1273 \mathrm{~K}$ have been computed based on experimentally determined phase relations and recent thermodynamic measurements on $\mathrm{Pt}_{1-x} \mathrm{Rh}_{x}$ alloys and $\mathrm{Rh}_{2} \mathrm{O}_{3}$. The composition dependence of the oxygen partial pressure for the oxidation of $\mathrm{Pt}_{1-x} \mathrm{Rh}_{X}$ alloys at different temperatures, and temperature for the oxidation of the alloys in air are computed. The diagrams provide quantitative information for optimization of the composition of $\mathrm{Pt}_{1-X} \mathrm{Rh}_{X}$ alloys for high temperature application in oxidizing atmospheres.
\end{abstract}

Keywords. System Pt-Rh-O; phase diagram; thermodynamic properties; Pt-Rh alloys; oxidation; stability field.

\section{Introduction}

Alloys of platinum and rhodium are extensively used in thermocouples for high temperature measurement, and as clean and inert heating elements in experimental high temperature furnaces. Phase diagram of the binary system, displayed in figure 1 , shows continuous solid solubility between the end members. An important limiting factor in the use of $\mathrm{Pt}-\mathrm{Rh}$ alloys is the temperature below which $\mathrm{Rh}$ in the alloy can be oxidized to form $\mathrm{Rh}_{2} \mathrm{O}_{3}$. In air, pure $\mathrm{Rh}_{2} \mathrm{O}_{3}$ is stable below $1315 \mathrm{~K}$ (Jacob and Sriram 1994). The thermodynamic stability window for $\mathrm{Pt}-\mathrm{Rh}$ alloys as function of temperature and oxygen partial pressure has not been quantitatively evaluated earlier. Recently, the standard Gibbs energy of formation of $\mathrm{Rh}_{2} \mathrm{O}_{3}$ (Jacob and Sriram 1994) and mixing properties of Pt-Rh alloys (Jacob et al 1998) have been determined accurately. Using these data, equilibrium conditions for the oxidation of $\mathrm{Pt}-\mathrm{Rh}$ alloys can be computed. This communication presents the computed thermodynamic stability domain for $\mathrm{Pt}-\mathrm{Rh}$ alloys against oxidation.

\section{Alloy-oxide equilibrium}

Platinum does not form a stable oxide at high temperature. To check if ternary oxides are stable in the system $\mathrm{Pt}-\mathrm{Rh}-\mathrm{O}$, mixtures containing $\mathrm{Pt}-\mathrm{Rh}$ alloy and $\mathrm{Rh}_{2} \mathrm{O}_{3}$ were equilibrated at $1273 \mathrm{~K}$ for $85 \mathrm{~h}$ in air. Alloys containing $10.2,20.7,30.5,39.6,48.8,59.3,69.5,80.6$ and 90.0 at.\% $\mathrm{Rh}$ were used in the equilibration studies.

*Author for correspondence
The alloys were made by arc melting $\mathrm{Pt}$ and $\mathrm{Rh}$ sponge of $99.9 \%$ purity on a water-cooled copper hearth. Each alloy button was remelted four times to ensure homogeneity. Alloy powders were prepared by filing. Iron particles in the powder were removed by a strong magnet. Residual iron was removed by chemical dissolution in acid. Fine powder of $\mathrm{Rh}_{2} \mathrm{O}_{3}$ used in equilibrium studies was of purity $>99.99 \%$. Equimolar mixtures of alloy and $\mathrm{Rh}_{2} \mathrm{O}_{3}$ were pelletized using a steel die before equilibration in air. After heat treatment, the pellets were examined by X-ray diffraction analysis (XRD) and optical microscopy. In pellets containing alloys with 10.2 and 20.7 at. \% $\mathrm{Rh}$, the oxide phase $\left(\mathrm{Rh}_{2} \mathrm{O}_{3}\right)$ was found to decompose. No change was detected in the phase composition of the other pellets. There was no evidence of formation of ternary condensed phases in the system Pt-Rh-O.

\section{Thermodynamic data}

\subsection{Pt-Rh alloys}

The relative excess chemical potential $\left(\Delta \mu_{\mathrm{Rh}}^{\mathrm{E}}\right)$ or excess partial molar free energy of mixing $\left(\Delta G_{\mathrm{Rh}}^{\mathrm{E}}\right)$ of $\mathrm{Rh}$ in $\mathrm{Pt}-\mathrm{Rh}$ alloys has been determined recently using an emf technique (Jacob et al 1998). The results at $1273 \mathrm{~K}$ can be expressed by the relation (Jacob et al 1998):

$$
\begin{aligned}
& \Delta \mu_{\mathrm{Rh}}^{\mathrm{E}}=\Delta G_{\mathrm{Rh}}^{\mathrm{E}}=R T \ln \gamma_{\mathrm{Rh}}= \\
&\left(1-X_{\mathrm{Rh}}\right)^{2}\left[-6,130+50 X_{\mathrm{Rh}}\right] \quad \mathrm{J} / \mathrm{mol} .
\end{aligned}
$$

From the Gibbs-Duhem equation, the relative excess 


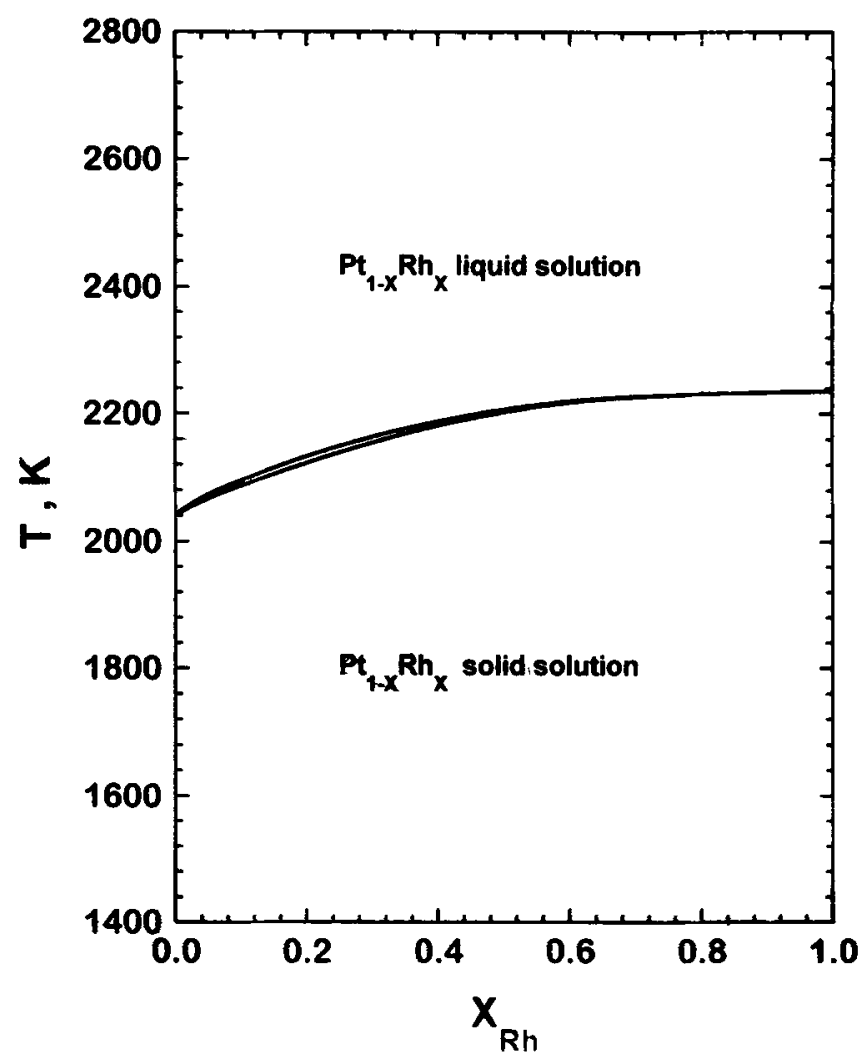

Figure 1. Phase diagram for the system Pt-Rh (Jacob et al 1998).

chemical potential of $\mathrm{Pt}\left(\Delta \mu_{\mathrm{PR}}^{\mathrm{E}}\right)$ and integral excess free energy of mixing of solid Pt-Rh alloys $\left(\Delta G^{\mathrm{E}}\right)$ at $1273 \mathrm{~K}$ were derived:

$$
\begin{aligned}
& \Delta \mu_{\mathrm{Pt}}^{\mathrm{E}}=\Delta G_{\mathrm{Pt}}^{\mathrm{E}}=R T \ln \gamma_{\mathrm{Pt}_{\mathrm{t}}}= \\
& X_{\mathrm{Rh}}^{2}\left[-6,155+50 X_{\mathrm{Rh}}\right] \mathrm{J} / \mathrm{mol}, \\
& \Delta G^{\mathrm{E}}=X_{\mathrm{Rh}}\left(1-X_{\mathrm{Rh}}\right)\left[-6,130+25 X_{\mathrm{Rh}}\right] \quad \mathrm{J} / \mathrm{mol} .
\end{aligned}
$$

The compositional dependence of excess partial entropy of mixing of $\operatorname{Rh}\left(\Delta S_{\mathrm{Rh}}^{\mathrm{E}}\right)$ was evaluated from the variation of emf with temperature (Jacob et al 1998):

$$
\Delta S_{\mathrm{Rh}}^{\mathrm{E}}=\left(1-X_{\mathrm{Rh}}\right)^{2}\left[-3 \cdot 80+0.031 X_{\mathrm{Rh}}\right] \quad \mathrm{J} / \mathrm{mol} \cdot \mathrm{K} .
$$

By combining the partial excess free energy at $1273 \mathrm{~K}$ with partial excess entropy, the partial enthalpy of mixing of $\mathrm{Rh}$ was obtained:

$$
\begin{aligned}
\Delta H_{\mathrm{Rh}} & =\Delta G_{\mathrm{Rh}}^{\mathrm{E}}+1273 \cdot \Delta S_{\mathrm{Rh}}^{\mathrm{E}} \\
& =\left(1-X_{\mathrm{Rh}}\right)^{2}\left[-10,970+90 X_{\mathrm{Rh}}\right] \mathrm{J} / \mathrm{mol} .
\end{aligned}
$$

From the Gibbs-Duhem equation, partial excess properties of $\mathrm{Pt}$ and integral excess mixing properties were obtained:

$$
\begin{aligned}
& \begin{aligned}
& \Delta S_{\mathrm{Pt}}^{\mathrm{E}}=X_{\mathrm{Rh}}^{2}\left[-3.8155+0.031 X_{\mathrm{Rh}}\right] \mathrm{J} / \mathrm{mol} \cdot \mathrm{K}, \\
& \Delta S^{\mathrm{E}}=X_{\mathrm{Rh}}\left(1-X_{\mathrm{Rh}}\right)[-3.80\left.\quad+1.55 \times 10^{-2} X_{\mathrm{Rh}}\right] \mathrm{J} / \mathrm{mol} \cdot \mathrm{K}, \\
& \Delta H_{\mathrm{Pt}}=X_{\mathrm{Rh}}^{2}\left[-11,015+90 X_{\mathrm{Rh}}\right] \mathrm{J} / \mathrm{mol}, \\
& \Delta H=X_{\mathrm{Rh}}\left(1-X_{\mathrm{Rh}}\right)\left[-10,970+45 X_{\mathrm{Rh}}\right] \mathrm{J} / \mathrm{mol} .
\end{aligned}
\end{aligned}
$$

Activities of component elements exhibit negative deviation from Raoult's law. Recent thermodynamic measurements (Jacob et al 1998) disprove the existence of solid state immiscibility below $\sim 1033 \mathrm{~K}$ shown in current phase diagram compilations (Moffatt 1976; Massalski et al 1990).

\section{$3.2 \mathrm{Rh}_{2} \mathrm{O}_{3}$}

The standard Gibbs free energy of formation of $\mathrm{Rh}_{2} \mathrm{O}_{3}\left(\Delta G_{\mathrm{f}}^{\mathrm{g}}\right)$ with orthorhombic structure has been measured recently using an advanced design of the solid state cell with three electrodes (Jacob and Sriram 1994). This arrangement minimizes polarization of the electrodes and gives more accurate values. The data in temperature range $850-1300 \mathrm{~K}$ can be represented by the relation:

$$
\Delta G_{\mathrm{f}}^{\mathrm{o}}\left(\mathrm{Rh}_{2} \mathrm{O}_{3}\right)=-3,96,365+282 \cdot 0 T( \pm 120) \quad \mathrm{J} / \mathrm{mol} .
$$

\section{Oxygen potentials for alloy-oxide equilibria}

The oxygen chemical potential corresponding to the equilibrium between the alloy and $\mathrm{Rh}_{2} \mathrm{O}_{3}$ can be computed as a function of composition of the alloy at different temperatures using the thermodynamic data. At a temperature $T$,

$$
\begin{aligned}
\Delta G_{\mathrm{f}}^{\mathrm{o}}\left(\mathrm{Rh}_{2} \mathrm{O}_{3}\right)= & R T \ln K=-R T \ln \frac{1}{a_{\mathrm{Rh}}^{2} \cdot P_{\mathrm{O}_{2}}^{3 / 2}} \\
R T \ln P_{\mathrm{O}_{2}}= & \Delta \mu_{\mathrm{O}_{2}}\left(\mathrm{Pt}_{1-X} \mathrm{Rh}_{X}+\mathrm{Rh}_{2} \mathrm{O}_{3}\right) \\
= & \frac{2}{3} \Delta G_{\mathrm{f}}^{\mathrm{o}}\left(\mathrm{Rh}_{2} \mathrm{O}_{3}\right)-\frac{4}{3}\left(R T \ln a_{\mathrm{Rh}}\right) \\
= & \frac{2}{3} \Delta G_{\mathrm{f}}^{\mathrm{O}}\left(\mathrm{Rh}_{2} \mathrm{O}_{3}\right)-\frac{4}{3}\left[\Delta H_{\mathrm{Rh}}+R T \ln X_{\mathrm{Rh}}\right. \\
& \left.-T \Delta S_{\mathrm{Rh}}^{\mathrm{E}}\right],
\end{aligned}
$$

where $\Delta \mu_{\mathrm{O}}$ is the oxygen chemical potential, $\Delta G_{\mathrm{f}}^{\mathrm{o}}\left(\mathrm{Rh}_{2} \mathrm{O}_{3}\right)$ the standarid Gibbs free energy of formation of $\mathrm{Rh}_{2} \mathrm{O}_{3}$, $P_{\mathrm{O}}$ the oxygen partial pressure, $a_{\mathrm{Rh}}$ the activity of $\mathrm{Rh}$, $X_{\mathrm{Rh}}^{2}$ the mole fraction of $\mathrm{Rh}$ in the alloy, and the other symbols have their usual meaning. The computed oxygen potentials are displayed in figure 2 as a function of 
composition at different temperatures. Conditions for oxidation of $\mathrm{Pt}-\mathrm{Rh}$ alloys at equilibrium can be readily evaluated from the diagram. At oxygen partial pressures above the curve the alloy will not oxidize. Rapid oxidation may result in depletion of $\mathrm{Rh}$ from the alloy surface, thus increasing the oxygen potential for further oxidation of the alloy.

Often Pt-Rh alloys are used in air and it is useful to know the temperature below which oxidation is feasible from a thermodynamic point of view for a given alloy composition. The temperature for oxidation in air can be computed from thermodynamic data for alloys and $\mathrm{Rh}_{2} \mathrm{O}_{3}$. Setting $\left(P_{\mathrm{O}_{2}} / P^{\mathrm{n}}\right)=0.21$ in (11) and rearranging:

$$
T=\frac{\left(\frac{2}{3} \Delta H_{f}^{\circ}\left(\mathrm{Rh}_{2} \mathrm{O}_{3}\right)-\frac{4}{3} \Delta H_{\mathrm{Rh}}\right)}{\left(\frac{2}{3} \Delta S_{f}^{0}\left(\mathrm{Rh}_{2} \mathrm{O}_{3}\right)-\frac{4}{3} \Delta S_{\mathrm{Rh}}^{\mathrm{E}}+\frac{4}{3} R \ln X_{\mathrm{Rh}}+R \ln 0 \cdot 21\right)},
$$

where $P^{\mathrm{o}}$ is the standard atmospheric pressure $\left(1.01 \times 10^{5} \mathrm{~Pa}\right)$. The computed curve is shown in figure 3. With increase in the concentration of $\mathrm{Rh}$ in the alloy,

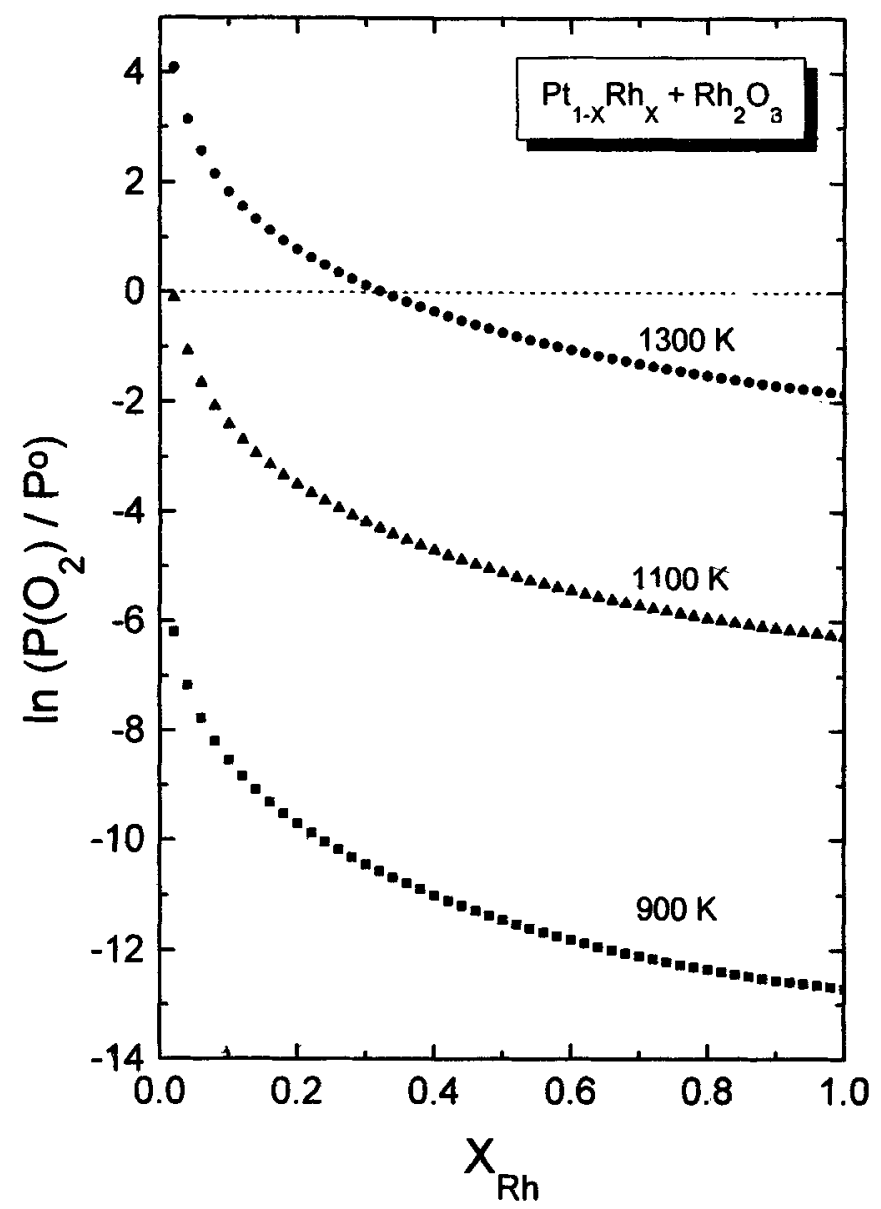

Figure 2. Variation of the equilibrium oxygen chemical potential for the formation of $\mathrm{Rh}_{2} \mathrm{O}_{3}$ as a function of composition of $\mathrm{Pt}-\mathrm{Rh}$ alloys at different temperatures. the temperature for the decomposition of $\mathrm{Rh}_{2} \mathrm{O}_{3}$ in air increases rapidly at low concentrations and more gradually at higher concentrations. The safe region for the use of $\mathrm{Pt}-\mathrm{Rh}$ alloys lies above the computed curve. Oxidation will not occur in this domain. Oxidation of alloys containing less than 15 at.\% $\mathrm{Rh}$ is limited by kinetic factors at temperatures below the curve. Oxidation will become significant with increasing concentration of $\mathrm{Rh}$ in the alloy, especially at $T>1200 \mathrm{~K}$.

\section{Ternary phase diagram of the system Pt-Rh-O}

Since the oxides of platinum are unstable in the experimental temperature range and ternary oxides do not exist in the system $\mathrm{Pt}-\mathrm{Rh}-\mathrm{O}$, isothermal sections of the phase diagram for the ternary system $\mathrm{Pt}-\mathrm{Rh}-\mathrm{O}$ at high temperatures can be constructed from the thermodynamic data using a free energy minimization algorithm (Morris and Stephenson 1986). The computed isothermal sections at 973 and $1273 \mathrm{~K}$ are displayed in figures 4 and 5, respectively. Phase diagrams at other temperatures can be readily calculated from the thermodynamic data. All

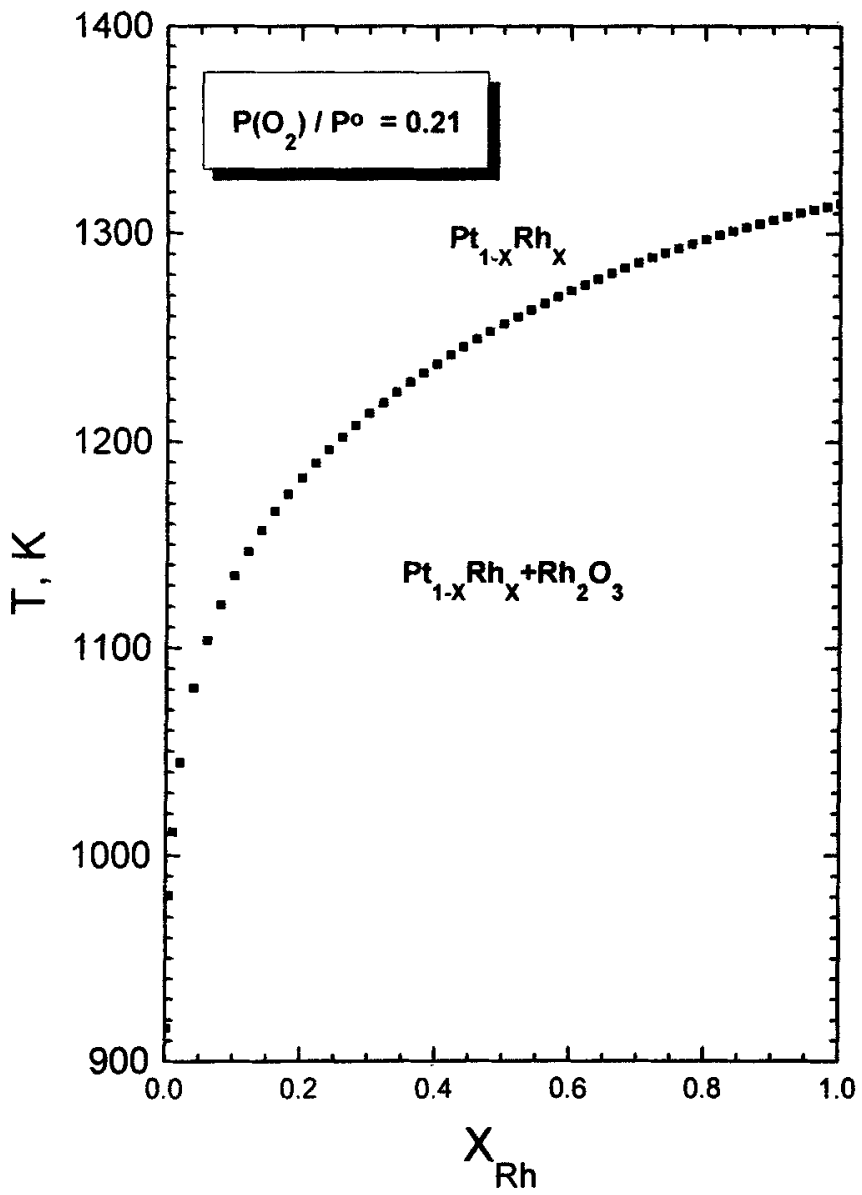

Figure 3. Variation of the equilibrium temperature for the oxidation of $\mathrm{Pt}-\mathrm{Rh}$ alloys in air $\left(P_{\mathrm{O}_{2}}=2.12 \times 10^{4} \mathrm{~Pa}\right)$. 


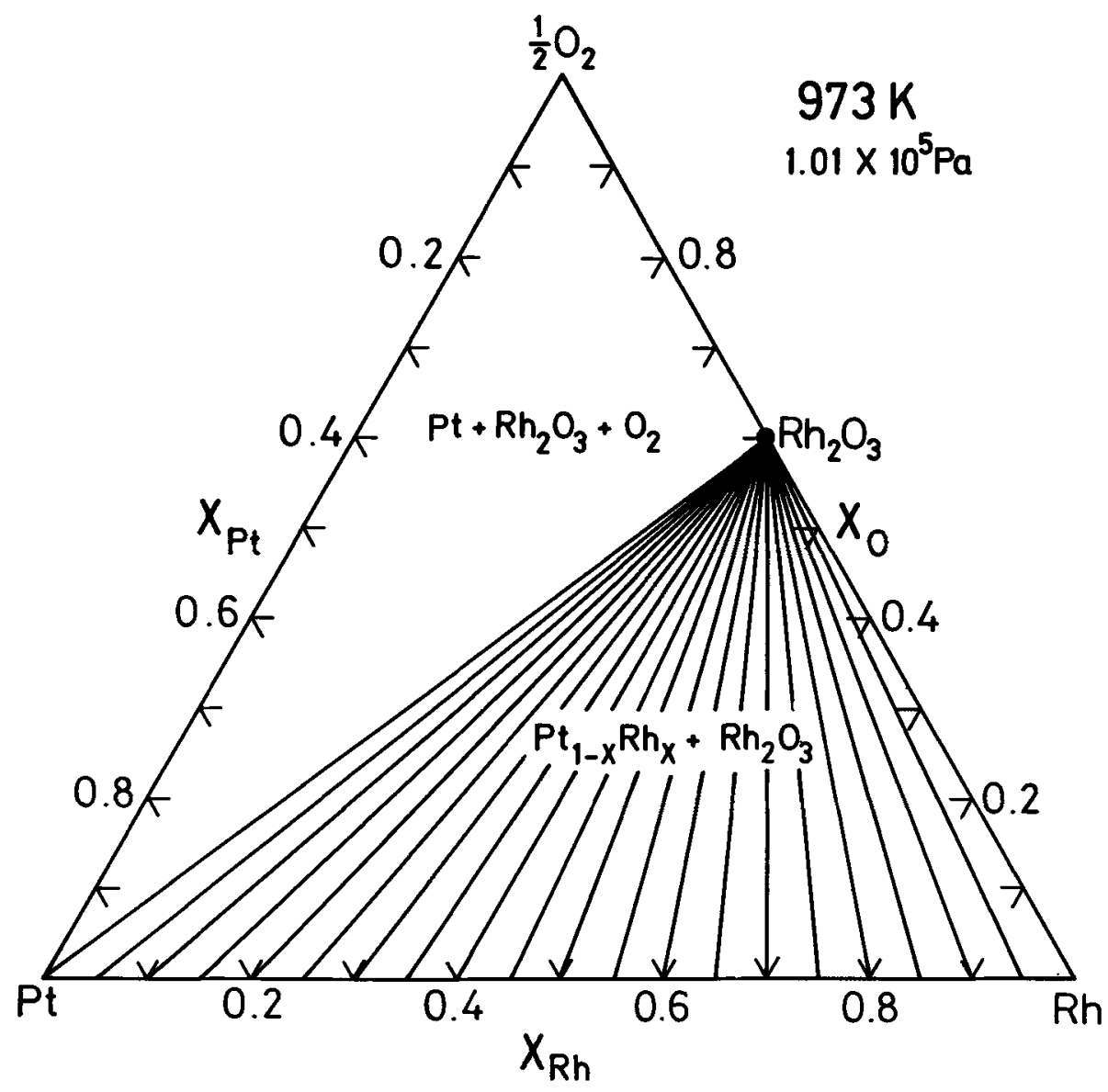

Figure 4. Isothermal section of the Pt-Rh-O system at $973 \mathrm{~K}$ computed from thermodynamic data.

Table 1. Temperature above which commercial $\mathrm{Pt}_{1-x} \mathrm{Rh}_{x}$ alloys will not be oxidized in air.

\begin{tabular}{ll}
\hline$X_{\mathrm{Rh}}$ & $\mathrm{T}, \mathrm{K}$ \\
\hline 0.06 & 1104 \\
0.13 & 1153 \\
0.30 & 1214 \\
0.40 & 1237 \\
0.60 & 1272 \\
\hline
\end{tabular}

the alloy compositions are in equilibrium with $\mathrm{Rh}_{2} \mathrm{O}_{3}$ at the lower temperature $(973 \mathrm{~K})$. There is a threephase equilibrium involving $\mathrm{Pt}, \mathrm{Rh}_{2} \mathrm{O}_{3}$ and $\mathrm{O}_{2}$ gas at $P_{\mathrm{O}_{2}}=1.01 \times 10^{5} \mathrm{~Pa}$. At the higher temperature $(1273 \mathrm{~K})$, an alloy containing $24 \mathrm{~mol} \% \mathrm{Rh}$ is in equilibrium with $\mathrm{Rh}_{2} \mathrm{O}_{3}$ and $\mathrm{O}_{2}$. The computed diagram is in agreement with phase equilibrium data obtained in the study, after correcting for the difference in the partial pressure of oxygen. Pt-rich alloys coexist with $\mathrm{O}_{2}$ gas at $1.01 \times 10^{5} \mathrm{~Pa}$ at $1273 \mathrm{~K}$. The alloy composition corresponding to threephase equilibrium between the alloy, $\mathrm{Rh}_{2} \mathrm{O}_{3}$ and $\mathrm{O}_{2}$ shifts to higher concentration of $\mathrm{Rh}$ with increasing temperature.
Use of Rh-rich alloys should be limited to temperatures above the oxidation limit. Although at low temperatures where oxidation is limited by kinetic factors, alloys can degrade at moderately elevated temperatures where oxidation is thermodynamically feasible and kinetics are favourable. The computed results provide valuable information for the intelligent use of Pt-Rh alloys in various high temperature environments containing oxygen. The lower thermodynamic limits for safe use of common alloy compositions in air are listed in table 1.

\section{Optimization of alloy composition}

Pt-Rh alloys are used as heating elements for furnaces that operate at temperatures higher than can be reached with pure Pt. An alloy containing $\sim 80$ at. $\% \mathrm{Rh}$ is the most suitable from the point of view of melting and recrystallization temperature. However, this composition is relatively more expensive and difficult to work mechanically. Significant improvement in melting and recrystallization temperatures can be achieved by alloying up to 40 at.\% $\mathrm{Rh}$. Wires of $\mathrm{Pt}_{0.6} \mathrm{Rh}_{0 \cdot 4}$ alloy are more easy to fabricate. This composition is also characterized 


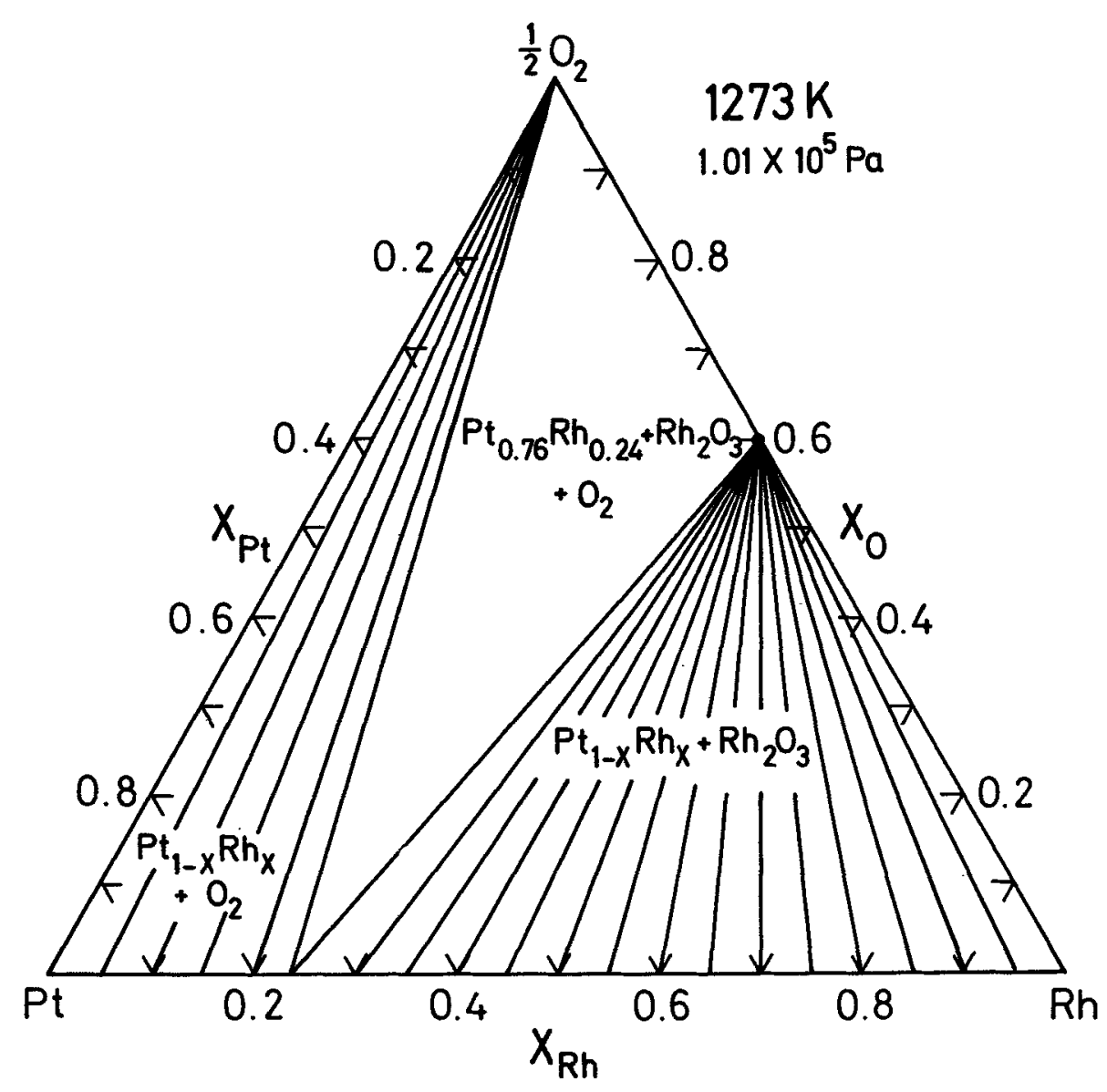

Figure 5. Isothermal section of the $\mathrm{Pt}-\mathrm{Rh}-\mathrm{O}$ system at $1273 \mathrm{~K}$.computed from thermodynamic data.

by a high value for electrical resistivity and a relatively low value for temperature-coefficient of resistance (Acken 1934). However, prolonged use in air at $1237>\mathrm{T} / \mathrm{K}>1000$ is not recommended because of its propensity for oxidation. At temperatures below $1000 \mathrm{~K}$, the alloys may remain untarnished for significant periods because of kinetic factors.

\section{Conclusion}

The thermodynamic stability domain of Pt-Rh alloys at high temperatures and in atmospheres containing oxygen has been computed using recent thermodynamic data on alloys and oxides (Jacob and Sriram 1994; Jacob et al 1998). The diagrams provide a quantitative guide for the use of Pt-Rh thermocouples and heating elements in oxidizing atmospheres. The prolonged use of $\mathrm{Pt}-40 \%$ $\mathrm{Rh}$ alloys in air is not recommended below $1237 \mathrm{~K}$.

\section{References}

Jacob K T and Sriram M V 1994 Metall. Mater. Trans. A25 1247

Jacob K T, Priya S and Waseda Y 1998 Metall. Mater. Trans. A29 (in press)

Massalski T B, Subramanian P R, Okamoto $H$ and Kaeprzak L (eds) 1990 Binary alloy phase diagrams (Materials Park, OH, USA: ASM International) Vol. 3

Moffatt W G 1976 and updates Handbook of binary phase diagrams (New York: General Electric Co.)

Morris A E and Stephenson J 1986 J. Metals 3841

Acken J S 1934 J. Res. Bur. Stand. 12249 